\title{
MODELLING OF MATURATION SYSTEMS FOR PORCINE OOCYTE in vitro
}

\author{
T.I. Kuzmina1, D.A. Novichkova1, N.A.Volkova ${ }^{2}$ \\ ${ }^{1}$ All-Russia Research and Development Institute of Farm Animal Genetics and Breeding, RAAS, St.Petersburg-Pushkin 196601, Russia \\ e-mail:prof.kouzmina@mail.ru,live8avis@mail.ru \\ ${ }^{2}$ All-Russia Research and Development Institute for Livestock Husbandry, RAAS, Dubrovitsy 142132, Moscow province, Russia \\ e-mail:natavolkova@inbox.ru
}

Received January 15, 2013

Sum mary

A system of extracorporal maturation of growing and fully grown oocytes have been developed on the basis of research of a role of structural elements of porcine follicles in formation of mature oocytes and a preventive estimation of the functional status of oocytes (BCB-test). The cultivation of oocytes in the developed system allows to receive till $45 \%$ of embryos at the stages of late morulae and blastocysts.

Keywords: cell technology of reproduction, pig, oocytes, embryos, fertilization in vitro, BCB-test.

Creation of biologically valuable pig embryos (native or reconstructed) by a simple method in vitro can be used in innovative cellular reproductive techniques (embryo transfer, transgenesis, cloning, embryonic stem cells) and their implementation in pig breeding, biomedicine, and pharmacology (1-3). Today a basic approach to the method is developed and applied to produce the offspring from oocytes cultured in vitro, but the outcome of oocytes at metaphase II in this case is lower than those obtained in vivo (4). Fertilization of porcine oocytes matured in vitro is often associated with polyspermy and violations in the formation of male pronucleus (5). The resulting number of blastocyst embryos is insufficient for experiments on creation of embryonic stem cell lines. All these facts underlie the development of effective systems for maturation of porcine oocytes in vitro and high outcome of mature oocytes.

The purpose of this study was modeling in vitro the system for maturation of porcine oocytes completely grown in vivo or in vitro based on markers of nuclear-cytoplasmic maturation of oocytes (chromatin status and mitochondrial activity) for their use in cell reproduction techniques.

Technique. Oocyte-cumulus complexes (OCC), somatic cells of ovarian follicles, and pre-implantation embryos were derived from Landrace pigs (6-8 months age). OOC were aspirated from follicles with a diameter of 3-5 mm. Follicle walls were examined for vascuolarization and turgor. Follicular fluid was aspirated from follicles with a diameter of 3-5 mm showing high turgor and an extensive capillary bed. Selection of OCC for experiments, evaluation of their quality, isolation of follicle membranes and follicular fluid, determination of fluorescence intensity in oocytes were performed using MitoTracker Orange CMTMRos (M 7510; Molecular Probes, "Eugene, OR", USA) following the methods described previously $(6,7)$. The fluorescence intensity (uA/oocyte) was measured using a fluorimeter (Nikon Photometry System P 100, "Nikon", Dusseldorf, Germany). Procedures of culturing pig oocytes and fertilization in vitro, as well as culturing of preimplantation embryos were conducted according to previously developed recommendations (6). Functional state of the original population of porcine oocytes was assessed by BCB-test using the method described earlier in bovine oocytes and modified by reducing the content of working solution of brilliant cresyl blue (B-5388, "Sigma", USA) to $13 \mathrm{mM}$ and treatment time to 60 minutes (8). After the exposure to BCB, the oocytes with blue cytoplasm were counted as completely grown (BCB+), unstained - as growing (BCB-). The state of chromatin in oocytes and embryos was assessed by the method of A. Tarkowski (9). Three systems of culturing were compared during the experiment: I - using a synthetic medium NCSU 23 (North Carolina State University) prepared following the prescription of R.M. Petters and K.D. Wells (1993) and described in guidelines (6), with the addition of human chorionic gonadotropin and horse chorionic gonadotropin (10 IU of each) (base model $\mathrm{BM}$, control); in the other variants, BM was added with: II $-10 \%$ follicular fluid (FF, follicles of $3-5$ mm diameter), III - follicle wall (FW, follicles of 3-5 mm diameter), IV - 10\% FF and FW.

The obtained results were compared using Pearson's chi-square test or Student's t-test (statistical software Sigma Stat). Reliability of differences of mean values were evaluated at three levels of significance $-\mathrm{P}<0,05 ; \mathrm{P}<0,01 ; \mathrm{P}<0,001$ in $3-5$ independent experiments.

Results. The general scheme of the experiments is shown in Figure.

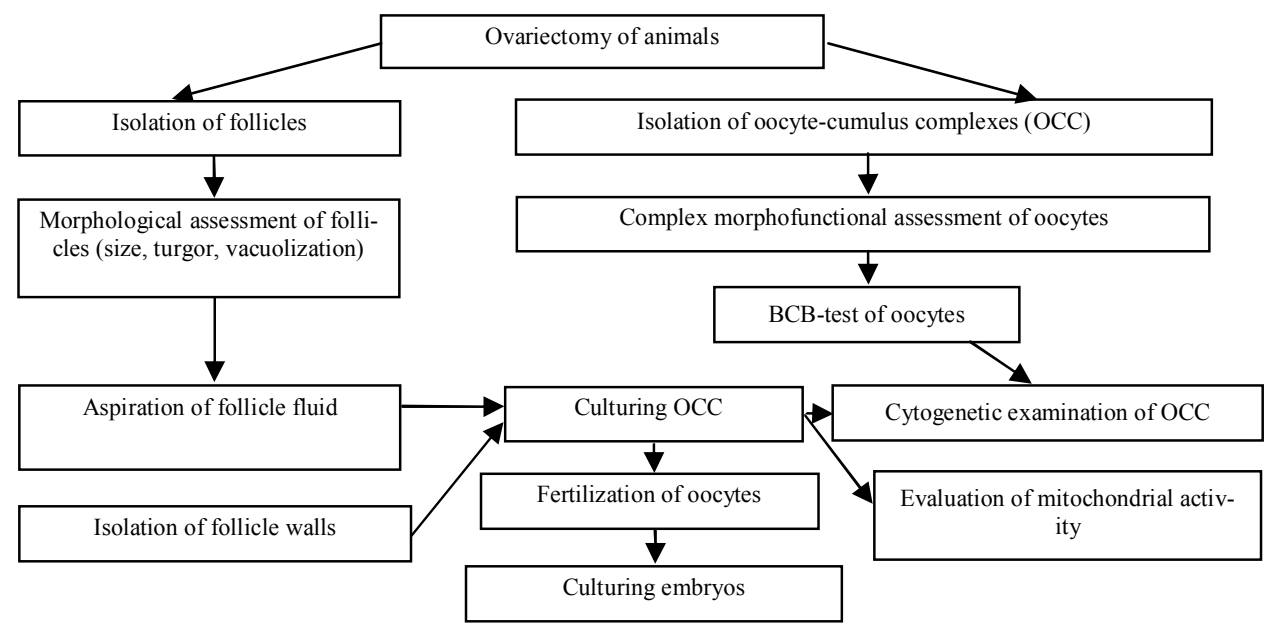


Simulated systems of oocyte maturation are an important instrument of embriotehnology. The development of embryos outside the body principally depends on conditions of culturing in vitro and their similarity to physiological process (10, 11). The population of oocytes isolated from the ovaries of donor pigs was heterogeneous. Testing oocytes with BCB vital dye as indicator of glucose-6-phosphate dehydrogenase (G6PDH) allows selecting the proper cells for further culturing, fertilization and embryogenesis. $\mathrm{BCB}$ reveals intracellular activity of G6PDH - the key enzyme of pentose phosphate cycle important for cell growth. Activity of this enzyme is high in growing oocyte and it reduces by the end of the growth. Non-toxicity of BCB dye was proved by experiments on sheep oocytes regardless of their size that were tested for a competence to meiotic maturation (12). In the earlier work it was found that porcine follicles of 3-5 mm diameter contain 71\% completely grown oocytes (BCB+) and 29\% - growing ones (BCB-) (7). In vivo oocytes maturate in a follicle where the functional activity of its structural elements (cells of theca and granulosa) and FF ensure correct meiotic maturation and formation of a mature egg cell. In this regard, pig oocytes were simulated for maturation in vitro using follicle wall and follicular fluid added as components to the culture media. The experiments were performed on completely grown and growing oocytes according to BCB-test.

1. Parameters of porcine oocyte maturation at 44-hour culturing in different systems

\begin{tabular}{|c|c|c|c|c|c|c|}
\hline \multirow{3}{*}{ Culturing system } & \multirow{3}{*}{ BCB-test } & \multicolumn{5}{|c|}{ Number of oocytes (percentage, $\%$ ) } \\
\hline & & \multirow{2}{*}{ total } & \multicolumn{2}{|c|}{ meiosis } & \multirow{2}{*}{$\begin{array}{l}\text { at metaphase } \\
\text { II }\end{array}$} & \multirow{2}{*}{ degenerate } \\
\hline & & & not re-initiated & re-initiated & & \\
\hline \multirow{3}{*}{$\begin{array}{l}\text { NCSU } 23+\text { hormones } \\
\text { (control) }\end{array}$} & 0 & 104 & $9(9)$ & $95(91)$ & $75(72)^{\mathrm{a}}$ & $28(27)$ \\
\hline & + & 99 & $8(8)$ & $91(92)$ & $77(78)^{b}$ & $25(25)$ \\
\hline & _- & 98 & $9(9)$ & $89(91)$ & $47(48)^{c}$ & $24(24)$ \\
\hline \multirow{3}{*}{$\begin{array}{l}\text { NCSU } 23 \text { + hormones + } 10 \\
\% \mathrm{FF}\end{array}$} & 0 & 102 & $8(8)$ & $94(92)$ & $81(79)^{d}$ & $23(23)$ \\
\hline & + & 100 & $7(7)$ & $93(93)$ & $83(83)^{\mathrm{e}}$ & $22(22)$ \\
\hline & - & 96 & $9(9)$ & $87(91)$ & $51(53)^{\mathrm{f}}$ & $22(23)$ \\
\hline \multirow{3}{*}{$\begin{array}{l}\text { NCSU } 23+\text { hormones }+ \\
\text { FW }\end{array}$} & 0 & 104 & $10(10)$ & $94(90)$ & $83(80)^{\mathrm{i}}$ & $24(23)$ \\
\hline & + & 98 & $7(7)$ & $91(93)$ & $82(84)^{k}$ & $22(22)$ \\
\hline & - & 95 & $8(8)$ & $87(92)$ & $48(51)^{1}$ & $22(23)$ \\
\hline \multirow{3}{*}{$\begin{array}{l}\text { NCSU } 23 \text { + hormones }+10 \\
\% \mathrm{FF}+\mathrm{FW}\end{array}$} & 0 & 105 & $9(9)$ & $96(91)$ & $85(81)^{\mathrm{m}}$ & $18(17)$ \\
\hline & + & 101 & $7(7)$ & $94(93)$ & $89(88)^{\mathrm{n}}$ & $15(15)$ \\
\hline & - & 98 & $9(9)$ & $89(91)$ & $57(58)^{\circ}$ & $16(16)$ \\
\hline
\end{tabular}

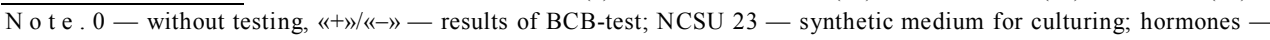
$10 \mathrm{MU}$ human chorionic gonadotropin + 10 MU horse chorionic gonadotropin; FL - follicular liquid (follicles of 3-5 mm diameter); FW - follicle walls (follicles of 3-5 mm diameter). Significance of differences of compared values (Student's t-test) for a:c; b:c; d:f; e:f; i:1; k:1; m:o; n:o P $<0,05$.

Table 1 shows the results of culturing the grown and growing oocytes in different systems. After $44 \mathrm{~h}$ of maturation, most of the oocytes in all groups re-initiated meiosis (91-93\%), while only 7-10\% cells remained at diplotene. The number of metaphase II oocytes was significantly different in control variant (not tested by $\mathrm{BCB}$ ) and all experimental groups with $\mathrm{BCB}+$ cells that completed growth before the start of culturing. In $78-88 \%$ of these oocytes (regardless of culturing system) was observed meiotic maturation. After 44 hours of culturing the growing oocytes, $48-58 \%$ of these cells developed the final stage of meiosis. It was also found no significant intergroup differences in number of oocytes with degenerated chromatin, which may indicate that immature oocytes can continue their development to metaphase II in vitro.

Formation of a grown oocyte capable for fertilization and subsequent development of the embryo is a complex transformation of chromatin (nuclear maturation) and ooplasm compartments. All processes in the cell are associated with energy metabolism and depend on oxidative phosphorylation. Functional activity of mitochondria reflects cytoplasmic maturation of the oocyte (13), which can be used in highly informative metabolic tests that show biological value of oocytes. Using intravital dyes, such as MitoTracker Orange CMTMRos M 7510 that specifically binds to active mitochondria, allows to estimate functional state of oocytes.

2. Fluorescence intensity in porcine oocytes after 44-hour culturing in different systems (MitoTracker Orange CMTMRos, uA/oocyte)

\begin{tabular}{|c|c|c|c|}
\hline Culturing system & BCB-test & $n$ & Fluorescence intensity \\
\hline \multirow{3}{*}{ NCSU 23 + hormones (control) } & 0 & 47 & $178,0 \pm 17,9^{\mathrm{a}}$ \\
\hline & + & 44 & $169,4 \pm 21,3^{\mathrm{b}}$ \\
\hline & - & 39 & $390,3 \pm 17,2^{\mathrm{c}}$ \\
\hline \multirow{3}{*}{ NCSU $23+$ hormones $+10 \%$ FF } & 0 & 45 & $181,3 \pm 18.6^{\mathrm{d}}$ \\
\hline & + & 41 & $151,1 \pm 17,1^{\mathrm{e}}$ \\
\hline & - & 38 & $395,4 \pm 21,2^{\mathrm{f}}$ \\
\hline \multirow[t]{3}{*}{ NCSU 23 + hormones + FW } & 0 & 45 & $168,9 \pm 18,1^{\mathrm{j}}$ \\
\hline & + & 41 & $142,0 \pm 22,8^{k}$ \\
\hline & - & 37 & $376,2 \pm 15,3^{1}$ \\
\hline \multirow[t]{3}{*}{ NCSU $23+$ hormones $+10 \% \mathrm{FF}+\mathrm{FW}$} & 0 & 45 & $158,4 \pm 15,1^{\mathrm{m}}$ \\
\hline & + & 44 & $118,9 \pm 17,4^{\mathrm{n}}$ \\
\hline & - & 37 & $281,0 \pm 15,7^{\circ}$ \\
\hline \multicolumn{4}{|c|}{ 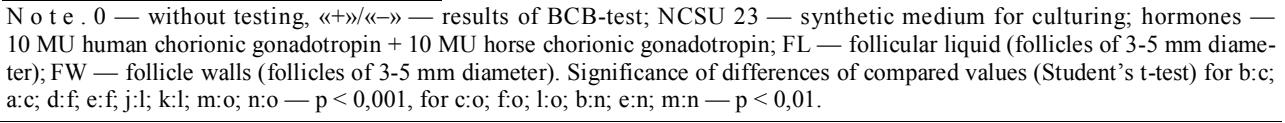 } \\
\hline
\end{tabular}

The comparison of fluorescence intensity on MitoTracker Orange CMTMRos M 7510 in grown and growing porcine oocytes after maturation in various experimental systems revealed significant differences between all groups (Table 2). By the end of culturing $(44 \mathrm{~h}), \mathrm{BCB}-$ oocytes exhibited high values of fluorescence in all the systems (Table 2). BCB- oocytes cultured in the medium with hormones, FF and FW showed lower intensity of fluorescence than those maturated in all other systems. It was observed the reliable difference in this parameter between the variant of $\mathrm{BCB}+$ oocytes cultured in the medium with hormones, $\mathrm{FW}$ and $\mathrm{FF}$, and $\mathrm{BCB}+$ oocytes cultured in the media with hormones and FF. So, the reduce in intensity of fluorescence of BCB vital dye recorded after culturing can be considered as the evidence of completed cytoplasmic maturation of the oocyte and preparation to blocking meiosis at metaphase II.

The efficiency of fertilization of porcine oocyte and culturing of resulting embryos (Table 3) was assessed with respect to the 
frequency of cleavage and development to late morulae and blastocysts. Thus was determined the system ensuring maturation of oocytes that completed growth both in vitro (BCB-) and in vivo (BCB+). The system provides high output of embryos at stages of late morulae and blastocysts (respectively 12 and 45\%) compared with other experimental groups (in which the rate was 3 to $21 \%$ ).

So, it was shown that the most effective maturation of porcine oocytes that completed growth in vivo or in vitro was obtained using the system with follicular fluid and follicle walls added to the medium. This system favorably affects maturation of oocytes in vitro and further development of embryos. The role of granulosa cells in this process is associated with their main function steroidogenesis and production of estradiol important for oocyte maturation. Therefore, the presence of somatic follicular cells (follicle wall) in a culture medium may lead to further increase in production of estradiol that promotes maturation of oocytes and their competence for fertilization and embryogenesis.

3. Parameters of preimplantation porcine embryos developed from oocytes completed growth in vivo and in vitro, at different systems of culturing

\begin{tabular}{|c|c|c|c|c|}
\hline \multirow{2}{*}{ Culturing system } & \multirow{2}{*}{ BCB-test } & \multicolumn{2}{|c|}{ Number of oocytes } & \multirow{2}{*}{$\begin{array}{l}\text { Number of morulae, } \\
\text { blastocysts, } n(\%)\end{array}$} \\
\hline & & total, $n$ & in cleavage, $n(\%)$ & \\
\hline \multirow[t]{3}{*}{ NCSU 23 + hormones (control) } & 0 & 109 & $23(21)^{\mathrm{a}}$ & $8(7)^{A}$ \\
\hline & + & 95 & $27(28)^{\mathrm{b}}$ & $11(12)^{\mathrm{B}}$ \\
\hline & - & 92 & $8(9)^{c}$ & 0 \\
\hline \multirow[t]{3}{*}{ NCSU 23 + hormones $+10 \% \mathrm{FF}$} & 0 & 103 & $32(31)^{d}$ & $12(12)^{\mathrm{D}}$ \\
\hline & + & 101 & $33(33)^{\mathrm{e}}$ & $15(15)^{\mathrm{E}}$ \\
\hline & - & 95 & $12(13)^{f}$ & $3(3)^{\mathrm{F}}$ \\
\hline \multirow[t]{3}{*}{ NCSU 23 + hormones + FW } & 0 & 97 & $36(37)^{\mathrm{j}}$ & $16(16)^{\mathrm{J}}$ \\
\hline & + & 99 & $41(41)^{k}$ & $21(21)^{\mathrm{K}}$ \\
\hline & - & 89 & $16(18)^{\mathrm{m}}$ & $4(4)^{\mathrm{M}}$ \\
\hline \multirow{3}{*}{$\mathrm{NCSU} 23+$ hormones $+10 \% \mathrm{FF}+\mathrm{FW}$} & 0 & 109 & $47(43)^{\mathrm{n}}$ & $34(31)^{\mathrm{N}}$ \\
\hline & + & 103 & $60(58)^{\circ}$ & $46(45)^{\mathrm{O}}$ \\
\hline & - & 98 & $24(24)^{\mathrm{p}}$ & $12(12)^{\mathrm{P}}$ \\
\hline
\end{tabular}

So, the authors have developed the system for extracorporeal maturation of oocytes that completed growth in vivo or in vitro. This system is based on preliminary assessment of functional state of the oocytes (BCB-test) and using the markers of nuclearcytoplasmic maturation (state of chromatin and mitochondrial activity); the oocytes are cultured in the medium containing follicular fluid and follicular walls as components added to the base medium. Under these conditions, the output of porcine embryos at stages of late morulae and blastocysts may be equal $45 \%$.

\section{REFERENCES}

1. Niemann H., Kues W., Carnwath J.W. Transgenic farm animals: current status and perspectives for agriculture and biomedicine. In: Genetic engineering in livestock: Ethics of Science and Technology Assessment. Springer, Berlin, v. 34, 2009: 1-30.

2. Whyte J.J., Prather R.S. Genetic modifications of pigs for medicine and agriculture. Mol. Reprod. Dev., 2011, 78: 879-891.

3. Ernst L.K., Volkova N.A., Zinov'eva N.A. Sel'skokhozyaistvennaya Biologiya [Agricultural Biology], 2009, 2: 4-9.

4. Coy P., Romar R., Ruiz S., Cánovas S., Gadea J., Vázquez F., Matás C. Birth of piglets after transferring of in vitro-produced embryos pre-matured with Rroscovitine. Reproduction, 2005, 129(6): 747-755.

5. Hunter M. Oocyte maturation and ovum quality in pigs. Rev. Reprod., 2000, 5: 122-130.

6. Kuz'mina T.I., Al'm Kh.,Torner Kh. Metody polucheniya embrionov svinei in vitro [Methods of In Vitro Production of Pig Embryos]. Sankt-Peterburg-Pushkin, 2008 .

7. Kuz'mina T.I., Murza G.V., Matashina O.P., Novikova N.O. Genetika i selektsiya v zhivotnovodstve: vchera, segodnya, zavtra [Compilation of Sci. Works: Genetics and Selection in Animal Husbandry]. Sankt-Peterburg-Pushkin, 2010: 207-212.

8. Kuz'mina T.I., Torner Kh., Al'm Kh. Dostizheniya nauki i tekhniki APK, 2010, 4: 66-68.

9. Tarkowski A. An air-drying method for chromosomal preparation from mouse eggs. Cytogenetics, 1966, 1: 394-400.

10. Yoshioka K., Suzuki C., Onishi A. Defined system for in vitro production of porcine embryos using a single basic medium. J. Reprod. Dev., 2008 Jun, 54(3): 208213.

11. Tareq K.M., Akter Q.S., Khandoker M.A., Tsujii H. Selenium and vitamin E improve the in vitro maturation, fertilization and culture to blastocyst of porcine oocytes. J. Reprod. Dev., 2012, 19(58/6): 621-628.

12. Rodriguez-Gonzalez E., Lopez-Bejar M., Velilla E., Paramio M.T. Selection of prepubertal goat oocytes using the brilliant cresyl blue test. Theriogenology, 2002, 57: $1397-1409$.

13. El Shourbagy S.H., Spikings E.C., Freitas M., St John J.C. Mitochondria directly influence fertilisation outcome in the pig. Reproduction, 2006 Feb, 131(2): 233245. 